EXPORTING REVOLUTION 


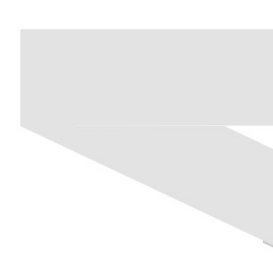




\section{EXPORTING REVOLUTION}

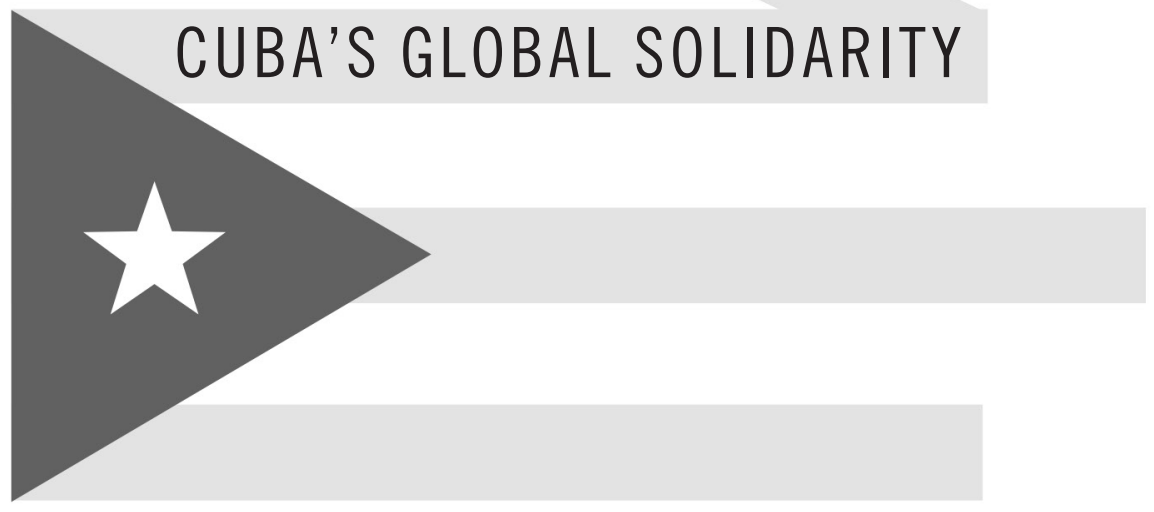

MARGARET RANDALL

DUKE UNIVERSITY PRESS

Durham and London | 2017 
(C) 2017 Duke University Press

All rights reserved

Printed in the United States of America on acid-free paper $\infty$

Text designed by Jennifer Hill

Cover designed by David Drummond

Typeset in Minion Pro by Westchester Publishing Services

Library of Congress Cataloging-in-Publication Data

Names: Randall, Margaret, [date] author.

Title: Exporting revolution : Cuba’s global solidarity / Margaret Randall.

Description: Durham : Duke University Press, 2017. | Includes bibliographical references and index.

Identifiers:

LCCN 2016044712 (print)

LCCN 2016047428 (ebook)

ISBN 9780822363842 (hardcover : alk. paper)

ISBN 9780822369042 (pbk. : alk. paper)

ISBN 9780822372967 (ebook)

Subjects: LCSH: Cuba-History-Revolution, 1959-Influence. |

Political culture-Cuba. | Cuba-Foreign relations. | Cuba-Relations-

United States. | United States-Relations-Cuba.

Classification: LCC F1788.R254 2017 (print) | LCC F1788 (ebook) |

DDC $972.9106 / 4-\mathrm{dc} 23$

LC record available at https://lccn.loc.gov/2016044712 
For Mark Behr

$1963-2015$

wise and courageous friend,

brilliant thinker, writer,

and teacher 
This page intentionally left blank 